Важно ещё отметить, что при компьютерной защите домашнего задания необходимо, чтобы ответ, полученный студентом, точно совпал с ответом, заложенным в программе. По нашему мнению, можно ограничиться тем, чтобы в ответе совпало должное число значащих цифр ( например, четыре ). Для этого студент должен получить ответ на конкретный вопрос в виде формулы, то есть в общем виде без подстановки чисел, обязательно проверить размерность полученных величин и лишь затем получить числовой результат с числом значащих цифр больше, чем требуется. После этого в качестве ответа следует представить, не округляя число, например: 31,12; или 2,317.

Таким образом, компьютерное тестирование студентов частично экономит время преподавателя. Он не занимается проверкой тестовых задач, то есть оценка теста является объективной. Но предварительная работа по подбору тестовых задач, их решению, оформлению и вводу в компьютерную программу требует больших затрат времени и творческих усилий преподавателя. Однако, если даже не все студенты группы приходят на объявленное заранее тестирование или приходят не изучив соответствующий раздел теоретической механики и для таких студентов приходится повторять тестирование, то и в этих случаях такой способ проверки знаний студентов с воспитательной точки зрения и с точки зрения экономии времени преподавателя является оправданным.

$$
* * *
$$

1. Кочанов Ф.П., Обносов К.Б. Материалы для семестровых заданий по теоретической механике. Часть 2. Москва. Изд-во ВА РВСН им. Петра Великого, 2004.

\title{
Васильева Д.Д. \\ Применение биометрической идентификации личности при онлайн оплате товаров и услуг
} Краснодарский филиал РЭУ им. Г.В. Плеханова doi: 10.18411/lj-04-2021-06 (Россия, Краснодар)

\section{Аннотация}

В статье рассматриваются актуальные вопросы, связанные с обеспечением надежной и легко реализуемой технологически, идентификации и верификации личности при использовании электронных платежных систем. Данная задача является актуальной в силу интенсивного развития электронных платежей, чему также способствовали карантинные меры, предпринятые в ответ на распространение коронавирусной инфекции. На текущем этапе развития в качестве одного из популярных вариантов обеспечения достоверной идентификации выступают биометрические методы. Рассмотрены и всесторонне проанализированы с технологической, правовой и организационно-экономической точек зрения, различные варианты биометрической идентификации. В результате анализа выявлены методы, применение которых позволит в значительной степени обеспечить необходимую достоверность идентификации при допустимых экономических затратах на организационно-технологическую составляющую.

Ключевые слова: электронные платежи, биометрическая идентификация, дистанционные технологии.

\section{Abstract}

The article discusses topical issues related to the provision of reliable and easily implemented technologically, identification and verification of a person when using electronic payment systems. This task is urgent due to the intensive development of electronic 
payments, which was also facilitated by quarantine measures taken in response to the spread of COVID infection. At the current stage of development, biometric methods are one of the popular options for ensuring reliable identification. Considered and comprehensively analyzed from the technological, legal, organizational and economic points of view, various options for biometric identification. As a result of the analysis, methods have been identified, the use of which will significantly ensure the necessary reliability of identification at acceptable economic costs for the organizational and technological component.

Keywords: electronic payments, biometric identification, remote technologies.

Прошедший 2020 год вошел в историю как год новых глобальных вызовов, связанных с появлением коронавирусной инфекции. Государства начали вводить карантинные меры для предотвращения худшего развития событий. Во многих странах вводились очень жесткие меры самоизолирования людей, так называемые локдауны (Lockdown). Вместе с тем, текущий 2021 год показал, что проблема приобрела затяжной характер, и периодические вспышки заболеваемости будут наблюдаться вплоть до приобретения популяционного иммунитета. Исходя из этого, люди были вынуждены срочно прибегнуть к новым дистанционным методам, практикам и технологиям для приобретения товаров повседневного спроса и продуктов питания, поддержания экономической активности, продолжения обучения школьников, студентов.

Рассмотрим технологические нововведения, которые продемонстрировали свою актуальность во время и после коронавирусной пандемии. Необходимо отметить, что технологии онлайн взаимодействия были доступны и до пандемии. Потребители, обладающие доступом в Интернет, могли зайти на соответствующие сайты и приобрести себе продукты питания и непродовольственные товары. Следует подчеркнуть, что в повседневной жизни до пандемии люди использовали данную возможность примерно на 30\%, так как психологически многим в обществе сложно воспринять специфику онлайн выбора вещей, продуктов и услуг. Многие потребители привыкли выбирать товары не только визуально, но и тактильно, оценивать упаковку, оставшийся срок годности, вести примерку понравившихся вещей, что не позволяет в полной мере формат онлайн магазина. Но в период, когда людей обязали по известным причинам сидеть дома, потребители были вынуждены приобретать товары онлайн, что сильно повлияло на востребованность онлайн форматов. На сегодня уже около 80\% населения России освоили возможности приобретения товаров онлайн. К счастью, финансовая сфера в Российской Федерации выдержала это стрессовое испытание. Широкое распространение в России электронных платежных систем и сервисов позволяет зачастую произвести оплату «не выходя из дома». Для большинства это стало уже чем-то абсолютно обыденным и привычным. Есть несколько возможных способов оплаты, например, через терминал курьеру при помощи платежной карты, через системы онлайн и мобильных платежей. Все эти технологии так или иначе решают задачи социального дистанцирования, ведь главная задача в пандемию остановить распространение инфекции, а значит максимально исключить контакты, не останавливая экономическую жизнь. Но интенсивное развитие технологий дистанционных и бесконтактных платежей порождает и новые задачи по обеспечению безопасности таких платежей, что напрямую влияет на устойчивость работы банков [1]. Одним из направлений обеспечения безопасности платежей является своевременная и безошибочная биометрическая идентификация владельцев платежных средств. Здесь необходимо тщательно разобраться во многих особенностях, что же такое биометрия, что входит в перечень биометрических данных, кто имеет право собирать биометрические данные и хранить их.

Итак, биометрическая идентификация - это процесс подтверждения личности, основанный на использовании индивидуальных физических признаков человека [2]. 
Биометрические параметры (биометрия) обладают следующими преимуществами: биометрия имеется абсолютно у каждого человека; биометрические данные не меняются с течением времени; биометрия уникальна; биометрические данные невозможно передать, утратить или украсть.

Биометрическая идентификация базируется на нескольких методах и признаках, основными из которых являются:

- код ДНК;

- формы кисти руки, лица, уха;

- папиллярные отпечатки пальцев;

- расположение вен кисти руки, лица;

- термограмма лица;

- сетчатка и радужная оболочка глаза;

- голос;

- почерк, клавиатурный почерк [3].

Распознавание дактилоскопическим способом представляется в виде соотношения уникальных папиллярных линий, находящихся на подушечках пальцев. Для такого вида методики используется специальные сканеры высокого разрешения, благодаря которым реализуется считывание до 70 индивидуальных точек. К минусам можно отнести лишь трудность в оцифровке столь небольшого изображения. Распознавание по радужной оболочке глаза осуществляется посредством сканирования радужки и является надежным способом. Распознавание сетчатки глаза осуществляется посредством сканирования ультракрасным излучением, что приносит большой дискомфорт обладателю данных. В отличие от радужной оболочки сетчатка не является надежной биометрической информацией, так как способна меняться в течении жизни, поэтому мы не наблюдаем широкой распространенности способа.

Идентификация по геометрии руки осуществляется посредством соотношения данных размера и изгиба фаланг пальцев, полнотой и широтой руки, а также расстоянием между суставами и сухожилиями.

Распознавание человека по форме уха осуществляется посредством лучевого преобразования. Это процесс, в ходе которого лучами считываются уникальные кодовые точки ушей и потом воспроизводятся в модельной форме.

Идентификация по венам руки осуществляется посредством специального инфракрасного рентгена. Гемоглобин, который содержится в крови человека, очень активно поглощает красное излучение, за счет чего проявляется уникальный узор расположения вен, который не меняется в течение всей жизни. Такой способ эффективный и широко распространён в крупных зарубежных компаниях.

Распознавание по голосу осуществляется при помощи сравнения частотных и статических характеристик голосового аппарата. Его достаточно сложно назвать надежным потому что речь человека легко воспроизвести в записи или смоделировать тембр голоса. С самого детства голос у каждого человека меняется вместе с его возрастом, поэтому такой метод может использоваться только как дополнительный.

Распознавание по геометрии лица осуществляется посредством сканирования около 30-40 показателей, таких как контур носа, губ, расстояние между бровями и т.д. Такой метод уже широко распространен, так как мы пользуемся им для разблокировки экранов телефонов, компьютеров и является одним из самых надежных за счёт большого количества уникальных точек.

В связи с большим количеством предлагаемых методов биометрической идентификации личности проанализируем их применимость для обеспечения идентификации при осуществлении электронных платежей. При этом следует рассматривать как организационно-технологические, так и правовые аспекты применения того или иного метода идентификации [4]. Большое значение в этом случае будет иметь соотношение: надежность идентификации - экономическая 
целесообразность. С этой точки зрения идентификация по коду ДНК не может получить массового распространения, так как не является быстрой и недорогой.

На данный момент для совершения покупок онлайн каждый человек может пользоваться дактилоскопическим способом и распознаванием по геометрии лица. Для этого даже не обязательно идти в банк, чтобы предоставить свои данные, достаточно просто привязать банковскую карту к телефону и при помощи выбранного способа разблокировки мобильного устройства подтвердить свои намерения об оплате товаров или услуг. Такой формат уже кажется нам привычным, но технологии прогрессируют и создаются новые возможности работы с биометрическими данными. Например, в России уже разработана система биометрической оплаты товаров в розничном формате обычного магазина. Для того чтобы что-то приобрести, потребителю нет необходимости брать наличность, банковские карты или телефон. По словам создателей таких технологий, чтобы начать ею пользоваться, необходимо сдать биометрические данные в многофункциональном центре, после чего можно будет оплачивать товары буквально «одним пальцем» [5]. Хранение биометрической информации осуществляется исключительным государственным органом, который не в праве предоставлять и распространять ее другим лицам. В свою очередь банки также стараются создать свои биометрические базы данных клиентов, пропагандируя использование биометрии при доступе к банкомату, платежному терминалу и т.д. [6]. Вместе с тем, биометрия является полноценным объектом правовых отношений и конфиденциальной информацией как в финансовой сфере [7], так и цифровой экономике в целом [8].

В заключении необходимо отметить, что для поддержания бизнеса в период пандемии большинству предпринимателей пришлось выйти на онлайн платформы, многие потребители были вынуждены обратиться к онлайн оплате товаров посредством электронных платежных систем. В скором времени процесс применения биометрии для идентификации станет обыденным и повсеместным, однако каждый должен помнить о том, что биометрические данные - это конфиденциальная информация, которую нельзя распространять и доверять другим лицам. Необходимо учитывать, что технологические инновации улучшают качество жизни, но, безусловно, постоянно требуют внимания и соответствующего организационно-правового сопровождения.

$$
* * *
$$

1. Верба С.Ю., Фролов Р.Н. Внедрение информационных технологий как стимулирующий фактор наращивания прибыли коммерческого банка // Вестник ИМСИТ. 2013. №3 - 4 (55 - 56). C.24 - 25 .

2. ГОСТ Р 51241-2008. Национальный стандарт Российской Федерации. Средства и системы контроля и управления доступом. Классификация. Общие технические требования. Методы испытаний [Электронный ресурс] // Tехэксперт [сайт]. - URL: http://docs.cntd.ru/document/1200071688 (дата обращения: 14.03.2021)

3. Сычев Ю.Н. Защита информации и информационная безопасность: учебное пособие / Ю.Н. Сычев. - Москва: ИНФРА-М, 2021. - 201 С.

4. Фролов Р.Н., Дудченко А.В., Колкарева И.Н. Актуальные проблемы стандартизации требований к верификации личности пользователя в сети при организации дистанционного обучения // Информационно-экономические аспекты стандартизации и технического регулирования. 2020. № 2 (54). - C. 65-71.

5. Камышев М.А., Марченко В.А., Глазырин С.А. Способ оплаты товаров и услуг с использованием биометрических параметров клиента и устройство для его осуществления // Патент № 0002589847 от 10.07.2016 [Электронный ресурс] URL: http://edrid.ru/rid/217.015.5b7d.html

6. Левченко В.А., Бондаренко В.В. Биометрические системы и их применение в банковском секторе Российской Федерации // В сборнике: Экономика, финансы, проектное управление и социальная сфера России: императивы устойчивости. 2018. - С. 22-28.

7. Kolkareva I.N., Dudchenko A.V., Eremeeva A.A., Frolov R.N. Automation of financial information exchange: implementation into the Russian legislation // Lecture Notes in Networks and Systems. 2020. T. 87. - C. 155-160.

8. Колкарева И.Н., Колмыков А.В. Идентификация человека в условиях цифровой экономики. Состояние и проблемы регулирования // Закон и право. 2020. № 8. - С. 53-55. 